\title{
Emotional Intelligence of Nurses in Tertiary Hospitals in Dali, the People's Republic of China
}

\author{
Yongling Hua ${ }^{1}$, Mohammad Abbas Uddin ${ }^{2, ~ *, ~ A n o w a r u l ~ J a l a l ~ B h u i y a n ² ~}$ \\ ${ }^{1}$ Spinal Surgery Department, First Affiliated Hospital of Dali University, Dali, the People's Republic of China \\ ${ }^{2}$ College of Nursing, Dhaka, Bangladesh
}

Email address:

uabbas9@gmail.com (M. A. Uddin)

${ }^{*}$ Corresponding author

\section{To cite this article:}

Yongling Hua, Mohammad Abbas Uddin, Anowarul Jalal Bhuiyan. Emotional Intelligence of Nurses in Tertiary Hospitals in Dali, the People's Republic of China. Advances in Bioscience and Bioengineering. Vol. 7, No. 3, 2019, pp. 32-36. doi: 10.11648/j.abb.20190703.12

Received: June 14, 2019; Accepted: July 10, 2019; Published: July 26, 2019

\begin{abstract}
Emotional intelligence plays an important role in regulating the emotions induced by fatigue or stress and it is critically required in nurses who work in dynamic hospital environments. Nurses' emotional intelligence helps them to create a positive work environment in various unfavorable situations in order to provide patients care in a supportive manner. The aim of this study was to assess nurses' emotional intelligence in tertiary hospitals in Dali, the People's Republic of China. The participants were 291 nurses working at two tertiary hospitals. Data were collected via the Demographic Data Form and the Chinese Wong and Law Emotional Intelligence Scale. Descriptive statistics were used to analyze demographic and emotional intelligence data. Results showed that, generally, nurses perceived high levels of emotional intelligence. More specifically, nurses perceived high levels of emotional intelligence in themselves and moderate levels of emotional intelligence in others. They also perceived moderate levels for their ability to regulate their own emotions and for their use of emotion to facilitate performance. This study provides essential information regarding nurses' emotional intelligence. Nurse managers should use this study's results to develop strategies that assist their nurses' efforts to improve emotional intelligence.
\end{abstract}

Keywords: China, Emotional Intelligence, Nurse

\section{Introduction}

Emotional intelligence is an individual's ability to accurately perceive, evaluate, and express emotions [1]. It consists of 4 dimensions: 1 ) self-emotional appraisal. This is the ability to sense, acknowledge, understand, and express one's own emotions; 2) others' emotional appraisal. This is the ability to perceive and understand the emotions of other people; 3) regulation of emotion in the self. This is the ability to regulate one's own emotions. People with this ability lose their temper less often and are more able to manage and recover from psychological distress; 4) use of emotion to facilitate performance. This is the ability to use emotions to benefit personal performance and support the establishment of activities. People with this ability use emotions to encourage themselves to do better and consistently focus their emotions in positive and productive ways.

Emotional intelligence is an important factor in effective job performance. It affects nurses' behavior and hospital practices (particularly patient care), the climate for care delivery, quality of service, and nurses' ability to deal with workplace conflict [2]. Nurses with higher emotional intelligence scores have demonstrated greater performance, longer careers, and a lower likelihood to change employer [3]. Nurses' emotional intelligence has a direct effect on the quality of hospital services [2]. Nurses interact with a variety of individuals, including professional colleagues, clients, and families, in a high-stress environment. Greater emotional intelligence among nurses leads to more positive attitudes, greater adaptability, improved relationships and increased orientation towards positive values [4]. Several studies have been conducted on nurses' emotional intelligence. In Iran, nurses reported high levels of emotional intelligence [2]. A study in Korea found that nurses perceived high levels of emotional intelligence [5]. In Turkey, nurses perceived moderate levels of emotional intelligence [6]. Chinese studies of emotional intelligence have reported inconsistent results. 
Nurses perceived high levels of emotional intelligence in Hebei province [7], but moderate levels in Shanghai and Xi'an provinces [8-9].

Dali is a city in Yunnan Province in southern China. It is populated by diverse ethnic groups with different religions, culture and lifestyles. Two tertiary hospitals provide inpatient, outpatient, and emergency health services Affiliated Hospital of Dali University and Dali Bai Autonomous Prefecture People's Hospital. Physicians and nurses work cooperatively and collaboratively, sharing responsibilities for problem-solving, decision-making, and the formulation and implementation of patient care plans [10]. However, physician-nurse collaboration is still disappointing in Chinese hospitals. Nurses have reported that they are perceived as subordinate to physicians and that nurse-physician communication was poor [11]. In a study of 386 nurses in six tertiary general university hospitals in Yunnan province, nurses perceived relationships with physicians as being at moderate levels [10]. Nursing work contains a huge number of scheduled activities and nonnursing activities. Furthermore, patients have high demands of nurses, expecting them to provide emotional support, diagnosis information, treatment planning, and nursing care [12]. Nurses also have to work overtime on routine nursing tasks and have inflated workloads due to nursing workforce shortages. Nurses with high workloads may report emotional exhaustion [13] and may be unable to regulate their emotions. Such nurses have reported frustration, disgust, anger, or sadness regarding their patients' situations. Subsequently, they were less likely to feel concern for physicians [14]. They were also less likely to control their emotions, potentially undermining effective communication between nurses, doctors, patients, and others. Strong emotional intelligence is essential for nurses in these situations because it can help them to manage difficult problems. People with robust emotional intelligence respond to stress better, are better at solving problems, have higher self-esteem and fewer behavioral problems, and are generally able to handle their own emotions better. Their emotional intelligence helps them solve problems in flexible and creative ways, even in highly stressful situations.

However, there have been no studies of nurses' emotional intelligence in Dali, Yunnan Province. Such a study is desirable and the findings will provide basic information which nurse administrators can use to investigate strategies that support their nurses' emotional intelligence.

\section{Data and Methods}

A descriptive study design was used to examine the level of nurses' emotional intelligence. The target population was the nurses at two tertiary hospitals in Dali, Yunnan, China: Affiliated Hospital of Dali University and Dali Bai Autonomous Prefecture People's Hospital. A sample size of 298 nurses was calculated using the Yamane formula [15]. The sample inclusion criteria were: 1) had worked as a nurse in the selected hospital for at least one year, and 2) was involved in providing direct care to patients. The exclusion criteria were: 1) had worked as a manager or charge nurse, and 2) was due to be on vacation or maternity leave, or be studying, during the study.

Self-reported data were collected from the nurses. Two instruments were used. The Demographic Data Form and the Chinese Wong and Law Emotional Intelligence Scale. The scale consisted of 16 items across 4 dimensions: 1) self-emotion appraisal (4 items), 2) others' emotion appraisal (4 items), 3) use of emotion (4 items), and 4) regulation of emotion (4 items). Each item requires a 7 -point Likert-type scale response $(1=$ totally disagree to $7=$ totally agree). Higher scores represent higher emotional intelligence (EI) [2]. The total scores ranged from 16-112. Total scores were classified as one of three levels: $16-47=$ low level of EI; $48-80=$ moderate level of EI; 81-112 $=$ high level of EI. This questionnaire's reliability was confirmed (Cronbach's alpha coefficient $=.88$ ). Cronbach's scores for the four dimensions were: self-emotion appraisal $=0.89$, use of emotion $=0.88$, regulation of emotion $=0.76$ and others' emotion appraisal $=0.85$.

Data from seven participants were partial and were discounted. Data from the remaining 291 participants were analyzed using a statistical program (SPSS 13.0). Descriptive statistics, including frequency, percentage, mean, and standard deviation were used to analyze the nurses' demographic and emotional intelligence secondary data.

\section{Results}

Table 1. Demographic Information of Nurses $(n=291)$.

\begin{tabular}{|c|c|c|}
\hline Demographic Information & Frequency (n) & Percentage (\%) \\
\hline \multicolumn{3}{|c|}{ Age (Mean 31.56, Range $=21-55$ years $)$} \\
\hline $20-30$ & 168 & 57.73 \\
\hline $31-40$ & 92 & 31.62 \\
\hline $41->50$ & 31 & 10.65 \\
\hline \multicolumn{3}{|l|}{ Gender } \\
\hline Female & 289 & 99.31 \\
\hline Male & 2 & 0.69 \\
\hline \multicolumn{3}{|l|}{ Marital status } \\
\hline Single & 61 & 20.96 \\
\hline Married & 225 & 77.32 \\
\hline Divorced & 5 & 1.72 \\
\hline \multicolumn{3}{|l|}{ Education level } \\
\hline Associate degree & 115 & 39.52 \\
\hline Diploma degree & 17 & 5.84 \\
\hline Bachelor's degree & 159 & 54.64 \\
\hline \multicolumn{3}{|l|}{ Working unit } \\
\hline Medical & 96 & 32.99 \\
\hline Surgical & 86 & 29.55 \\
\hline Pediatric & 20 & 6.87 \\
\hline Obstetric and Gynae & 13 & 4.47 \\
\hline Operating room & 18 & 6.19 \\
\hline Emergency room & 19 & 6.53 \\
\hline Intensive care unit & 16 & 5.50 \\
\hline $\begin{array}{l}\text { Out-patient department } \\
\text { Job status }\end{array}$ & 23 & 7.90 \\
\hline Junior nurse & 107 & 36.77 \\
\hline Senior nurse & 129 & 44.33 \\
\hline Nurse-in-Charge & 52 & 17.87 \\
\hline Associate chief nurse & 3 & 1.03 \\
\hline $\begin{array}{l}\text { Working experience } \\
<5 \text { years }\end{array}$ & 55 & 18.90 \\
\hline
\end{tabular}




\begin{tabular}{lll}
\hline Demographic Information & Frequency (n) & Percentage (\%) \\
\hline $5-10$ & 141 & 48.45 \\
$11-20$ & 62 & 21.31 \\
$21->30$ & 33 & 11.34 \\
Working shift & & \\
Day shift & 64 & 21.99 \\
Rotating shift & 227 & 78.01 \\
Employment status & & \\
Permanent nurses & 101 & 34.71 \\
Temporary nurses & 190 & 65.29 \\
\hline
\end{tabular}

As per Table 1, the majority of subjects were female, aged between 21 and 55. The average age was 31.56 years and more than half of the subjects were between 20 and 30 years old. Most subjects were married (77.32\%). 54.64\% of subjects held a bachelor's degree, with $39.52 \%$ holding an associate degree. $36.77 \%$ of subjects were junior nurses and $44.33 \%$ were senior nurses. Almost fifty per cent of the sample had between 5- and 10-years' experience. 32.99\% worked in medical departments and $29.55 \%$ worked in surgical departments. Most subjects (78.01\%) worked rotating shifts. $34.71 \%$ were permanently employed and $65.29 \%$ were temporary staff.

Table 2. Emotional Intelligence of Nurses $(n=291)$.

\begin{tabular}{llll}
\hline Variable & Mean $(\mathbf{M})$ & Standard Deviation (S.D.) & Level \\
\hline Emotional Intelligence & 81.32 & 12.13 & High \\
\hline
\end{tabular}

As per Table 2, overall, participants reported a high level of emotional intelligence $(\mathrm{M}=81.32$, S.D. $=12.13)$.

Table 3. Categories of Emotional Intelligence of Nurses $(n=291)$.

\begin{tabular}{llll}
\hline Variable & Frequency & Percentage & Mean (M) \\
\hline \multirow{3}{*}{ Emotional Intelligence } & 2 & .7 & Between 16 and 47 \\
& 140 & 48.1 & Between 48 and 80 \\
& 149 & 51.2 & Between 81 and 112 \\
\hline
\end{tabular}

As per Table 3, the highest proportion (51.2) of participants reported a high level of emotional intelligence.

Table 4. Level of Dimensions of Emotional Intelligence of the Nurses ( $n=291)$.

\begin{tabular}{llll}
\hline Dimensions of Emotional Intelligence & Mean $(\mathbf{M})$ & SD & Level \\
\hline 1. Self-emotional appraisal & 22.80 & 3.48 & High \\
2. Others' emotional appraisal & 19.57 & 5.45 & Moderate \\
3. Use of emotion to facilitate performance & 19.76 & 3.94 & Moderate \\
4. Regulation of emotion in the self & 19.20 & 4.33 & Moderate \\
\hline
\end{tabular}

The mean score and standard deviation of each dimension of the subjects' emotional intelligence are shown in Table 4. Possible scores for each dimension of emotional intelligence are between 4 and 28. The nurses reported the highest score in the dimension of self-emotional appraisal $(\mathrm{M}=22.80, \mathrm{SD}$ $=3.48$ ), while the dimensions of others' emotional appraisal $(\mathrm{M}=19.57, \mathrm{SD}=5.45)$, use of emotion to facilitate performance $(\mathrm{M}=19.76, \mathrm{SD}=3.94)$, and regulation of emotion in the self $(\mathrm{M}=19.20, \mathrm{SD}=4.33)$ were all at moderate levels.

\section{Discussion}

Nurses in this study reported a high level of emotional intelligence $(\mathrm{M}=81.32$, S.D. $=12.13)$. This is consistent with previous studies of nurses in Iran [2] and Ghana [16] and a study of clinical nurses in Hubei, China [7]. The high emotional intelligence scores of nurses in this study may partly attributable to the demographic characteristics of the subjects. Studies have proposed that women have greater emotional intelligence than men [17-18]. In this study, 99.3\% of subjects were women (Table 1). They may, therefore, be better able to recognize, analyze and respond to emotions, and cope with difficult situations than male nurses. Age may be another important factor. Older individuals generally score higher on emotional intelligence than younger ones [19]. In the present study, the average subject age was 31.56 (the middle-adult period) so the participants' increased maturity may have been reflected in greater emotional control. Education level may be another possible explanation for this finding, as $54.6 \%$ of subjects held bachelor's degrees. People with high education levels may have more chance to learn sociology, psychology, interpersonal and communication skills, and aesthetics; subjects which may improve selfawareness and enhance confidence [20], potentially leading to greater emotional intelligence.

In terms of the specific dimensions of emotional intelligence, nurses in this study scored highly for their ability to appraise their own emotions $(\mathrm{M}=22.80, \mathrm{SD}=$ 3.48) and moderately for their abilities to appraise others' emotions $(\mathrm{M}=19.57, \mathrm{SD}=5.45)$, use emotion to facilitate performance $(\mathrm{M}=19.76, \mathrm{SD}=3.94)$, and regulate emotion in the self $(M=19.20, S D=4.33)$.

The nurses perceived that they had high levels in the dimension of self-emotional appraisal (Table 4). This is consistent with the study of nurses in Hubei, China [7]. It is probable that occupation is a key factor in this result. In China, nurses are expected to provide emotional support to patients and families in addition to providing care to patients [22]. Nurses recognize their own emotions and are likely to refrain from expressing negative emotions they are experiencing. Having a conscious relationship to their 
emotions, they may also accede more easily to signals about what is right and wrong in decision-making [21]. They are also more likely to enhance patients' trust and respect. Regardless of the situation, nurses are well-advised to keep their emotions in check, and emotional awareness can contribute to that ability [23].

It is important that nurses regulate their emotions and modulate their own behavior based on their evaluations of other's thoughts and emotions [25]. Nurses in the present study perceived that they had a moderate ability to appraise others' emotions. It may be that high workloads undermine their ability to sense, interpret, and understand the emotions of others. Perhaps, they simply do not have time to detect and appraise the emotion of others or even to listen to patients as much as they might wish to.

Subjects reported a moderate ability to use emotion to facilitate performance. This may be because of the participants' education levels. 54.6\% held a bachelor's degree and most had worked as nurses for more than five years. Therefore, they probably had a good knowledge of nursing theory combined with experience of patient care and would have developed an understanding of patients' conditions and emotional responses. They should be able to set goals and motivate themselves to achieve them. However, that they did not perceive this ability to be higher may be related to nurses' position within Chinese medical organizations, specifically in their working relationship with physicians, whose instructions they must follow during patient care. Nurses are often regarded as assistants of physicians and have less autonomy and control over patients' health and care. Although nurses may have their own opinions, they must always defer to the physician. Nurses' opinions are often ignored, and their suggestions are rarely implemented. At a systemic level, therefore, many nurses simply don't have the autonomy to use emotion to facilitate performance. Secondly, it is likely that nurses feel frustration when their ideas are inconsistent with the physicians and are not implemented. This can undermine their confidence in their abilities and they may struggle to inspire themselves [24]. This may explain why the subjects perceived a moderate ability to use emotion to facilitate performance.

In the present study, the nurses perceived that they had a moderate ability to regulate their own emotions. This may be because they struggle to understand others' emotions or to use emotions to facilitate performance. Conceivably a lack of understanding of others, a lack of control, and reduced confidence in their own abilities exacerbate the stress and frustration they face due to staff shortages and high workloads.

\section{Conclusion}

Overall, participants reported high levels of emotional intelligence. In respect of the dimensions of emotional intelligence, nurses perceived a high ability to appraise their own emotions, a moderate ability to appraise others' emotions, moderate use of emotion to facilitate performance, and moderate regulation of their own emotions. These results may be useful for nurse administrators who wish to develop strategies that support nurses to improve emotional intelligence. Study should be conducted to explore the relationship between emotional intelligence and sociodemographic characteristics. Further study focusing on hospital factors which may affect emotional intelligence is recommended.

\section{List of Abbreviations}

$\mathrm{EI}=$ Emotional intelligence.

$\mathrm{M}=$ Mean.

$\mathrm{SD}=$ Standard deviation.

Ethical Considerations

Permission was obtained from the two tertiary level hospital authorities. Written consent was given by all study participants.

\section{References}

[1] C. S. Wong and K. S. Law. "The effects of leader and follower emotional intelligence on performance and attitude: An exploratory study" Leadership Quarterly, vol. 13, pp. 243-274, 2002.

[2] M. R. Ezzatabadi, M. A. Bahrami, F. Hadizadeh, M. Arab, S. Nasiri, M. Amiresmaili, and G. A. Tehrani. "Nurses' emotional intelligence impact on the quality of hospital services" Iranian Red Crescent Medical Journal, vol. 14 (12), pp. 758, 2012.

[3] E. Codier, C. Kamikawa, B. M. Kooker, and J. Shoultz. "Emotional intelligence, performance, and retention in clinical staff nurses" Nursing Administration Quarterly, vol. 33 (4), pp. 310-316, 2009.

[4] A. Kristin, and Elisabeth. "Emotional intelligence: A review of the literature with specific focus on empirical and epistemological perspectives" Journal of Clinical Nursing, vol. 16 (8), pp. 1405-1416, 2007.

[5] M. Kim, and H. Choi. "Structural equation modeling on nurses' emotional labor including antecedents and consequences" Journal of the Korean Data and Information Science Society, vol. 27 (1), pp. 143-154, 2016.

[6] C. Basogul, and G. Ozgur. "Role of emotional intelligence in conflict management strategies of nurses" Asian Nursing Research, vol. 10, pp. 228-233, 2016.

[7] L. R. Tao, and G. L. Song. "Study on the correlation of emotional intelligence and job performance of clinical nurses" Journal of Nursing Administration, vol. 12 (8), pp. 533-540, 2012.

[8] J. Z. Hu, J. Zhu, and X. J. Zhang. "Influence of nurses' emotional intelligence on emotional labour strategy" Journal of Shanghai Nursing, vol. 13 (3), pp. 5-7, 2013.

[9] Q. Ma, T. Feng, and J. Xin. "Study on relationship among emotional intelligence, positive emotion and job involvement of nurses" Chinese Nursing Research, vol. 30 (1), pp. 120121, 2016. 
[10] J. H. Liu. "Research progress on the status of nurse-physician collaboration" Medical Information, vol. 8, pp. 3780-3781, 2011.

[11] X. L. Kong, and W. W. Liu. "The correlation between doctornurse cooperation and job satisfaction among emergency department nurses" Chinese Nursing Managrment, vol. 9 (9), pp. 13-16, 2009.

[12] S. H. Zhao. "Quality nursing care as perceived by nurses and patients in the second teaching hospital of Harbin Medical University in the people's Republic of China (Unpublished master' thesis)" Chiang Mai University, Thailand, 2006.

[13] E. Greenglass, R. Burke, and L. Fiksenbaum. "Workload and burnout in nurses". Journal of Community \& Applied Social Psychology, vol. 11 (3), pp. 211-215, 2001

[14] S. Stordeur, W. D'hoore, and C. Vandenberghe, C. "Leadership, organizational stress, and emotional exhaustion among hospital nursing staff" Journal of Advanced Nursing, vol. 35 (4), pp. 533-542, 2001.

[15] T. Yamane. "Statistic: An introductory analysis" Tokyo: Harper International, 1973.

[16] T. Tagoe, and E. N. B. Quarshie. "The relationship between emotional intelligence and job satisfaction among nurses in Accra" Nursing Open, vol. 4 (2), pp. 2016.

[17] L. A. Downey, V. Papageorgiou, and C. Stough. "Examining the relationship between leadership, emotional intelligence and intuition in senior female managers" Leadership \& Organization Development Journal, vol. 27 (4), pp. 250-264, 2006.
[18] N. Extremera, P. Fernandez-Berrocal, and P. Salovey. "Spanish version of the Mayer-Salovey-Caruso emotional intelligence test (MSCEIY) Version 2.0: reliabilities, age and gender difference". Psicothema, vol. 18, pp. 42-48, 2006.

[19] I. Nikolaou, and I. Tsaousis. "Emotional intelligence in the workplace: Exploring its effects on occupational stress and organizational commitment" The International Journal of Organizational Analysis, vol. 10 (4), pp. 327-342, 2002.

[20] X. Yuan. "The influence of "Nursing aesthetics" for emotional intelligence of bachelor degree students" Shanxi Medical University, 2007.

[21] K. Akerjordet, and E. Severinsson. "Emotional intelligence in mental health nurses talking about practice" International Journal of Mental Health Nursing, vol. 13 (3), pp. 164-170, 2004.

[22] Q, R. Cao, J. M. Li, and Y. Li. "Effects of emotional intelligence on nurses' performance" Nursing Research: Middle Edition, vol. 4, pp. 968-969, 2011.

[23] E. J. Rojell, C. E. Pettijohn, and R. S. Parker. "Emotional intelligence and dispositional affectivity as predictors of performance in salespeople" Journal of Marketing Theory and Practice, vol. 14 (2), pp. 113-124, 2006.

[24] G. H. Qiao, and N. Wang. "Survey on job satisfaction, career development and organizational support among nurses" Journal of Nursing Science, vol. 25, pp. 52-54, 2010.

[25] A. Coruk. "Emotion management manners of managers in terms of management processes (Unpublished doctoral dissertation)" Turkey, 2012. 